\title{
Development of the New Generation of Clamping Jaws for Thermomechanical Simulator
}

Tomáš Kalina, Václav Marek,

Regional Technological Institute, Faculty of Mechanical Engineering, University of West Bohemia, 30614 Pilsen. Czech Republic. E-mail: tkalina@rti.zcu.cz, marekv06@rti.zcu.cz

\begin{abstract}
This paper presents a development and design of new multifunctional clamping jaws for thermomechanical simulator. In the article there is presented what the thermomechanical simulator is and what is it used for. The article also describes the requirements for the thermomechanical simulator jaws and how they were achieved. All important parts of which the thermomechanical simulator jaws are assembled and used are described in detail. Finally, thermal simulations of the jaws were performed under operating loads. This technical solution is protected as a utility model registered on The Industrial Property Office - Czech Republic.
\end{abstract}

Keywords: Clamping jaws, thermomechanical simulator, heat treatment, forged parts

\section{Introduction}

The development and optimization of a heat treatment and mechanical working of forged parts would be very time-consuming and costly if carried out right in the production line. For this reason, a thermomechanical simulator has been developed. Using the simulator, mechanical loads, as well as loads from forces, deformation and heat acting on a real-life product during various manufacturing processes can be simulated. The paper [5] describes this testing system and the related methodology. The agreement between the characteristics of a real-life product and the data from the simulator is demonstrated using an example of a closed-die forging. The comparison involved mechanical properties and microstructures. Results achieved on numerous other products, such as sheet metal, rods, wires and others, prove that material-technological modelling with the aid of this newly-developed equipment is a cost-effective method of modelling reallife manufacturing processes in laboratory conditions [5].

This paper is focused on the development of a new generation of clamping jaws for a thermomechanical simulator. The clamping jaws are the main part of the thermomechanical simulator. There are many specific requirements for these jaws, so it was not possible to use jaws for example a tensile test machine or other clamping jaws available on the market.

\section{The thermomechanical simulator}

The thermomechanical simulator serves to simulate and optimize the processes of thermal and mechanical processing of forgings and other steel components. Using a thermomechanical simulator it is possible to simulate, for example, forging, quenching, tempering and other mechanical, force or deformation and temperature loads of test samples.

The simulator of thermomechanical processes is under long-term development at the departments of the Research Centre based at University of West Bohemia in Pilsen. Its primary purpose is laboratory-based simulation and optimization of real-world processes used in thermomechanical treatment of metals in industry. With this sys- tem, forming processes can be simulated while maintaining the required temperatures in the specimen. Thanks to long-standing experience and continuous development efforts, the equipment offers a good agreement between the outcomes of laboratory simulations and the characteristics of real-world forged parts made in actual production lines [5].

The simulator consists of three subsystems. Its core is the MTS FlexTestSE electro-hydraulic testing system which offers the maximum load of $50 \mathrm{kN}$ at actuator speeds of up to $3 \mathrm{~m} / \mathrm{s}$ with clamping jaws. Applying mechanical forces to the test piece, it is also the central control unit of the entire machine. It maintains two-way communication with those other two subsystems which control the specimen temperature [5].

The second subsystem is a specimen heating system. It relies on high-frequency electrical resistance heating. At its core there is a multi-stage controller as a single-chip computer and FPGA with a patented power converter control method [6]. The power source parameters are 230 $\mathrm{V} / 16 \mathrm{~A}$; the maximum current passing through the specimen is $1 \mathrm{kA}$. The controlled quantities include the current and the frequency. The frequency of the control loop is $16 \mathrm{kHz}$. Feedback is provided by a thermocouple attached to the test specimen. With the maximum power of the system of $3 \mathrm{~kW}$, specimens can be heated in a controlled manner at rates in excess of $200{ }^{\circ} \mathrm{C} / \mathrm{s}$, depending on the material and shape of the test piece. The accuracy of the specimen temperature is limited by the accuracy of the thermocouples. The variation is no more than $\pm 2{ }^{\circ} \mathrm{C}$ from the value indicated by the thermocouple [5].

The third subsystem of the simulator is the cooling system. Like the others, it is a feedback-based unit linked to the heating system. The heating system transmits digital data on the current specimen temperature and the set point temperature. If the specimen temperature is lower than the set point temperature, heating is activated. In the opposite case, the cooling system is activated automatically. The coolant is an air-water mixture of variable ratios applied at varying intensities. The control is based on an in-house non-linear algorithm. The program for the cooling system has been developed using LabView environment and runs on myRio. The maximum available controlled cooling rates are up to $100{ }^{\circ} \mathrm{C} / \mathrm{s}$ [5]. 

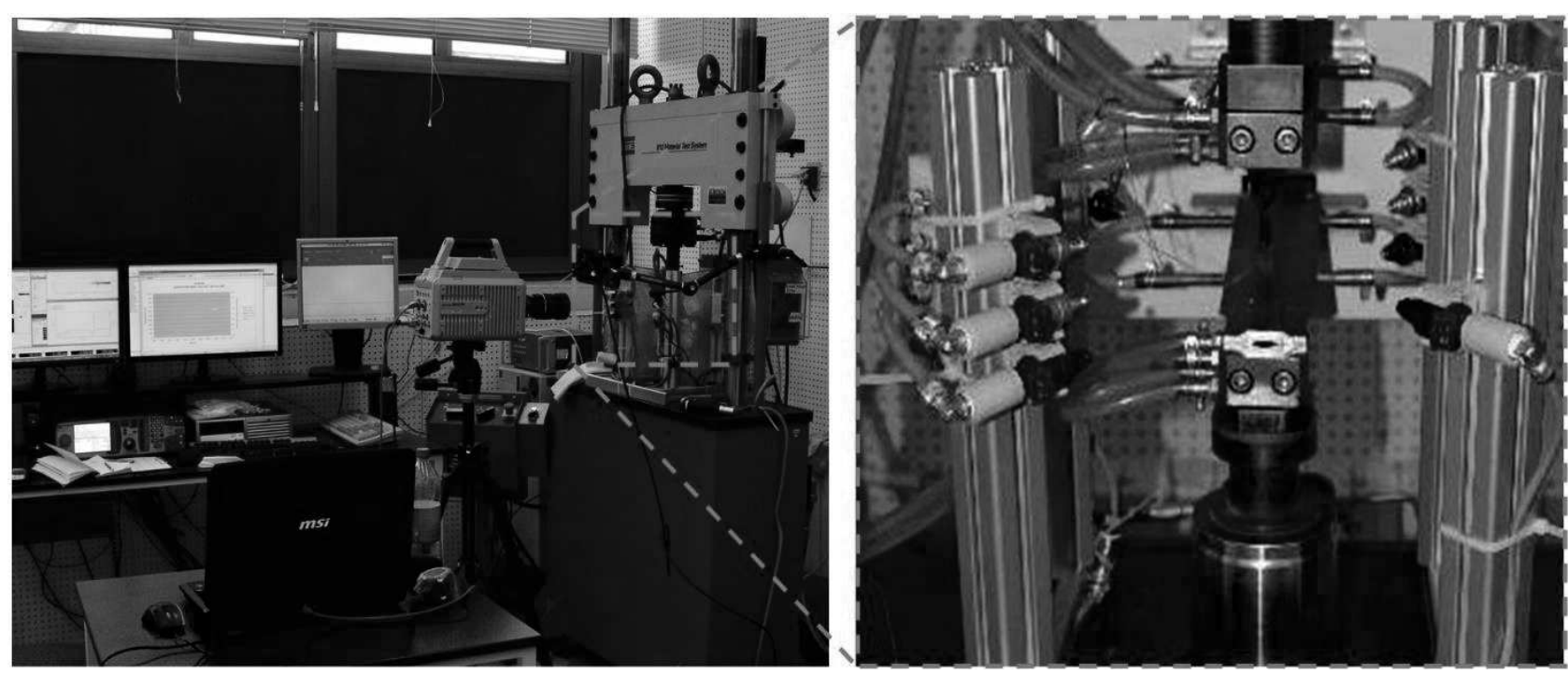

Fig. 1 Current solution of thermomechanical simulator

\section{Innovative solutions of clamping jaws}

\section{Requirements for the design solution}

There are many specific requirements for the jaws, so it was not possible to use jaws for example a tensile test machine or other clamping jaws available on the market.

Versatility is required for clamping different sample shapes. This is a simulation of a fast dynamic action, so it was important to put a lot of emphasis on light weight (to minimize inertial effects). The transition between tension and compression can be simulated. In addition, the deformation of the test specimen is measured, so the transition between tension and pressure must be backlash-free. (to minimize measurement errors). It is a simulation of forming at higher temperatures, therefore it is necessary to heat the sample in some way, cool it and monitor its current temperature. Both heating and cooling are required. For this reason, the material used to manufacture the jaws must not be susceptible to sudden changes in temperature and must not be damaged by these changes. As the use of electric resistance heating is necessary, the jaws must be additionally insulated. With regard to measurement accuracy, the jaws must be sufficiently rigid, backlash-free and temperature-stable to eliminate measurement errors. With regard to the operator's comfort and measurement efficiency, easy jaw remo$\mathrm{val} /$ assembly from/to the machine is required and of course easy and quick exchange of samples. All parts of the clamping jaws must be internally cooled.

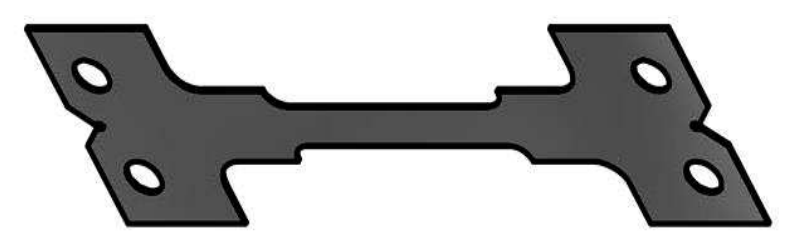

Fig. 2 Examples of clamped samples

\section{Secure:}

- versatility, for:
a) sheet samples $\mathrm{T}=1-12 \mathrm{~mm}$
b) cylindrical samples with threads M16
c) other additional devices

- low weight

- transition between tensile and compressive loads without backlash

- sufficient stiffness of all parts (for elimination of measurement errors)

- electrically insulated (lower part)

- internal cooling system of all parts of jaws

- thermal stability of used materials

- low sensitivity to rapid temperature change
- alignment of samples and clamping into the machine (elimination of bending moment)

- outlet of coolant

- easy operation (exchange of specimens)

- simple dis/mantling of the jaws to/from the machine

- low production costs

\section{Enable:}

- dynamic loads

- rapid heating of the specimens

- rapid cooling of the specimens (external)

- measurement of temperature of specimen 


\section{Design solution of clamping jaws}

The jaws were designed according to the above requirements and technological possibilities. The jaws consist of the upper and lower jaws, between which a sample is clamped.

Upper part of clamping jaws consists of a free and a fixed part. The fixed part is fixed to the moving traverse of the machine by means of a thread with fine pitch M27x2. After setting to the required position, the position is secured by preloading with lock nut.

The detachable jaw is fastened to the fixed jaw with 3 screws. The two fitting screws are oriented in a horizontal plane and ensure that the sample is clamped between the fixed and the detachable part. The third bolt is oriented parallel to the specimen axis and its prestressing eliminates movement of the detachable jaw from the fixed part. Given that the jaws must be universal for the range of samples, the bolt extends in a groove in the detachable part.

In addition, there are 2 threaded holes in the fixed jaw for this bolt. For bar specimens and flat specimens up to a thickness of $5 \mathrm{~mm}$, the elongated screw is fastened to the threaded hole nearer the axis. For flat specimens of 5$12 \mathrm{~mm}$ thickness, the bolt is then mounted in the second threaded hole farther from the axis.

Lower part of clamping jaws has the same design solution as upper part in terms of cooling system and clamping of specimens. The connection of the detachable and the fixed part of the jaw with 3 screws remains the same. However, the lower jaw is different in clamping into the machine and is additionally electrically insulated.

Electrical insulation of the lower clamping jaw is secured by an isolating disk which is clamped between the fixed part of the lower jaw and the flange. This disk is made of polymer PEEK GF30. This material was chosen due to its very good mechanical properties and high temperature stability.

The polymers have a small modulus of elasticity in tension/compression, therefore the isolating disk was designed as thin as possible (in this case $1 \mathrm{~mm}$ ) to minimize its deformation.

The upper and the lower part of the jaw must be electrically insulated, but coolant is sprayed on these parts at the same time. The running coolant could connect the upper and the lower part. Therefore, a $7 \mathrm{~mm}$ high collar was created on the thin isolating disk.

Flange is conected with lower fix jaw by 8pcs of bolts M6. Standard steel washers and polymer isolating washers are located under the bolt heads. The isolating washers are made of the same material as the above mentioned isolating disk.

The heads of the bolts that secure the flange to the lower jaw are countersunk in the flange. The flange has a cylindrical shape, but there are 2 flats on the sides for the possibility of tightening by means of a wrench.

Since the lower piston can be pivoted, the jaw is screwed into the piston and the preload of the screw connection is performed directly by preloading the flange relative to the piston. After clamping, the piston is rotated so that the front part of the jaw is turned towards the operator. A groove is formed on the lower surface of the lower jaw, which serves to drain coolant from the holes for the vertical screws.

All four parts of jaws have internal cooling system. In the fixed and the detachable part of the jaws, a "U-shaped" cooling circuit is created. Coolant enters and exits from the jaws on the left side, where it is fed via quick connectors.

The specimen is heated by high-frequency electrical resistance heating, which is applied by means of copper plates which are introduced between the fixed and the detachable part of the jaws.

The specimen is cooled by several nozzles which are directed at the sample. A combination of water and air nozzles is used to achieve the desired cooling rate.

Bar specimens are clamped using the M16 thread, which is made in both jaw counterparts. Flat (sheet metal) specimens are clamped by the frictional force between the contact surfaces of the jaws and the specimen, which is due to the preloading force of the bolt connection. For this reason, the contact surface of the detachable jaw is roughened to increase the coefficient of static friction. The flat specimens are secured by fitting bolts that pass through the holes in the specimens.
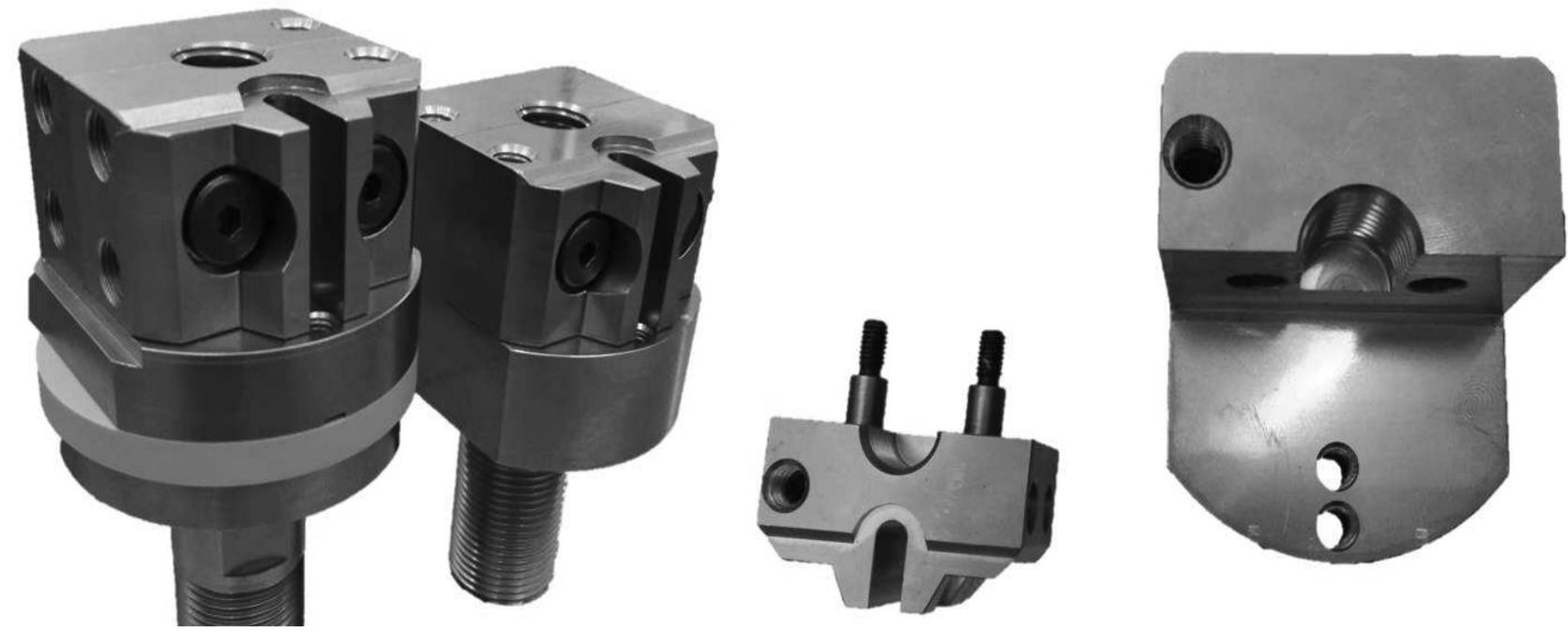

Fig. 3 Manufactured jaws 
Figure 4 shows an overall 3D model of the clamping jaws with a detail on the lower part of the clamping jaws.
Figure 5 shows partial cross-section views of jaws to visualize connections and functions.

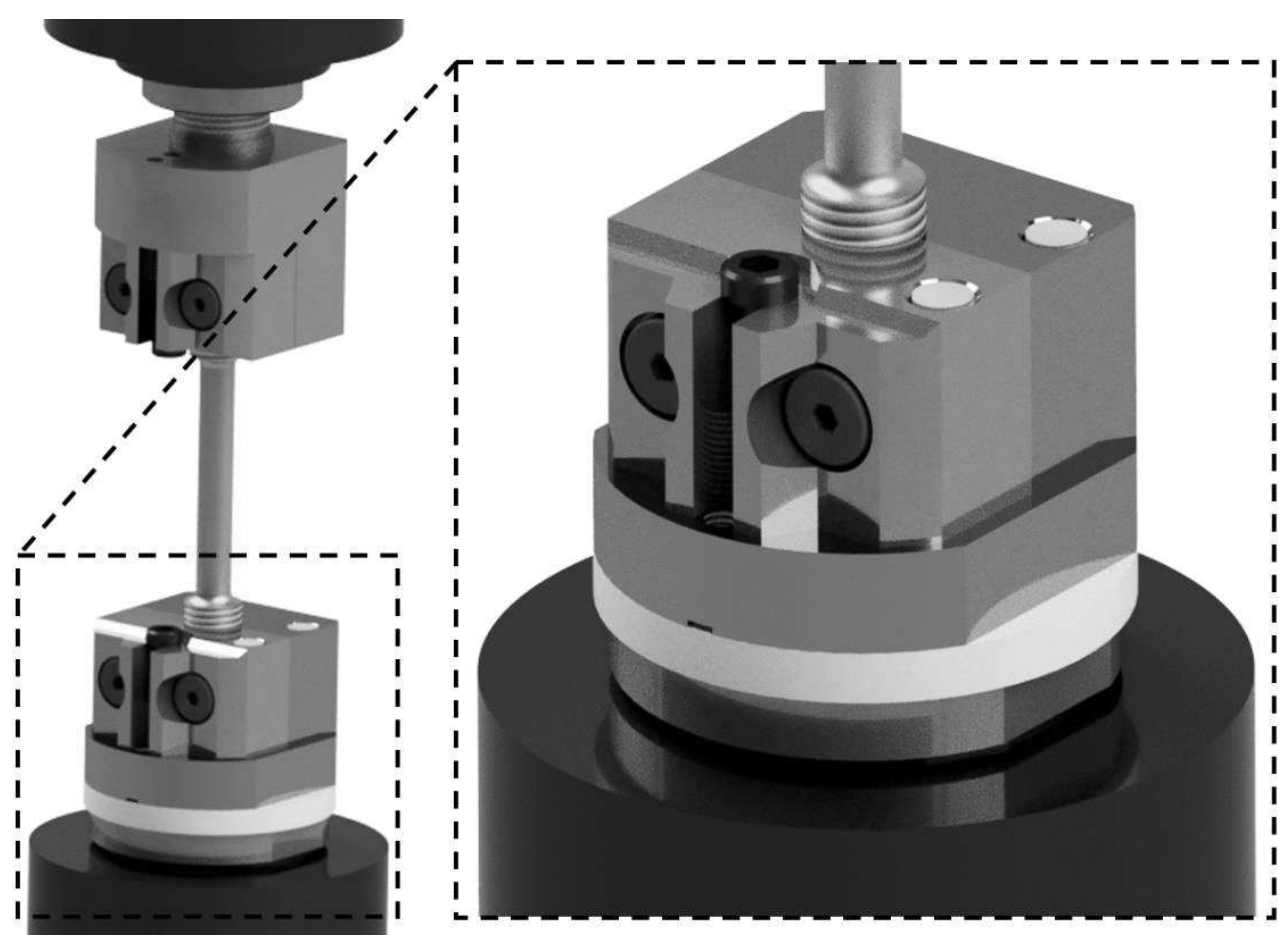

Fig. 4 3D model of clamping jaws assembly

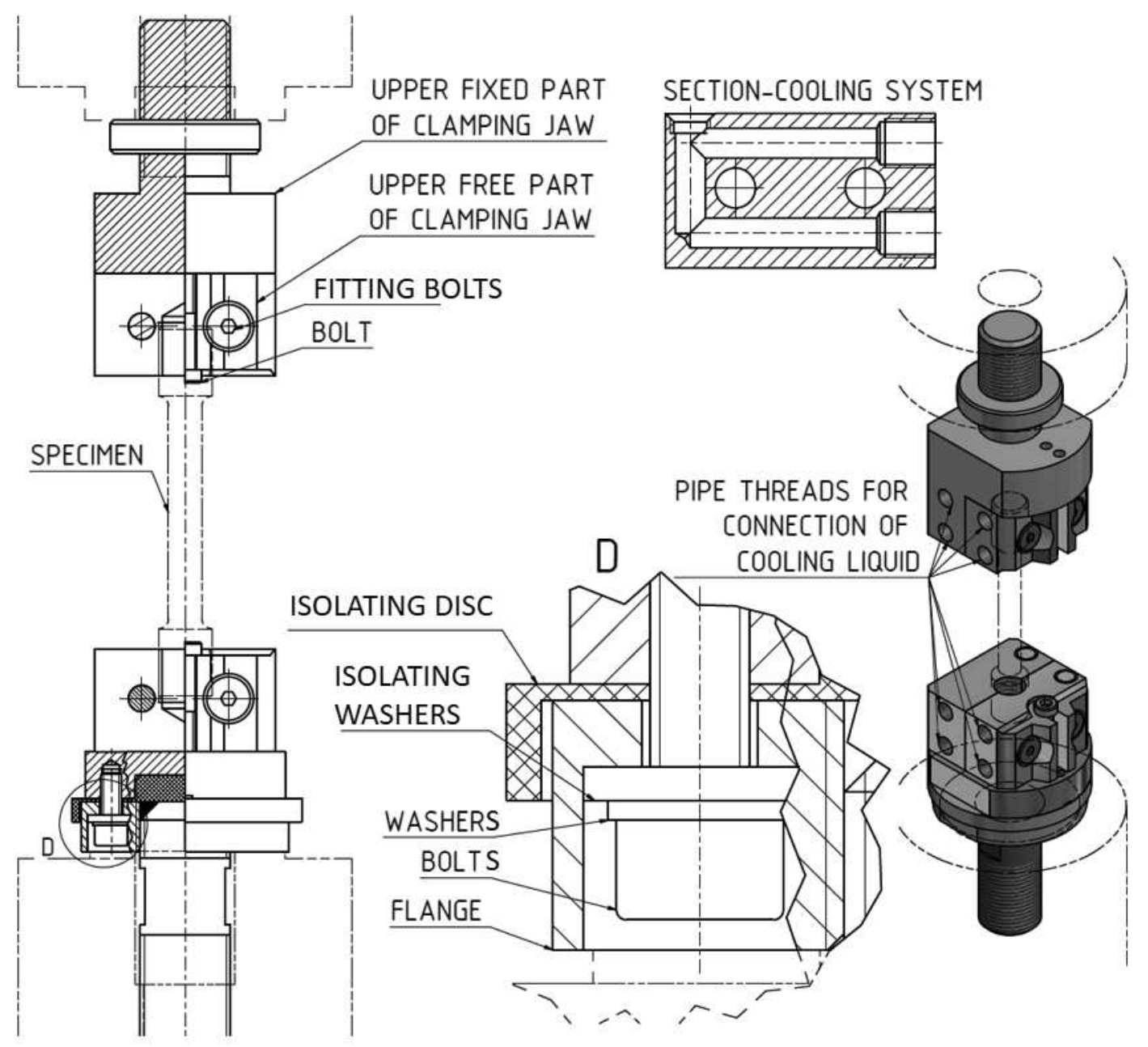

Fig. 5 Description of the main parts of the clamping jaw assembly 


\section{Thermal simulation}

The required temperature of holding jaws is under $30^{\circ} \mathrm{C}$. The required capacity of cooling system was simulated. The thermal simulation was launched in the simulation software Siemens NX12. A basic level of thermal simulation is represented by the Nastran solver. It is able to solve thermal fields, thermal transfer between parts and convection. Solved convection is based on thermal transfer coefficients [7]. An accuracy of thermal transfer simulation is highly dependent on predefined thermal transfer coefficients [8]. A steady state simulation and a transient solution are defined.

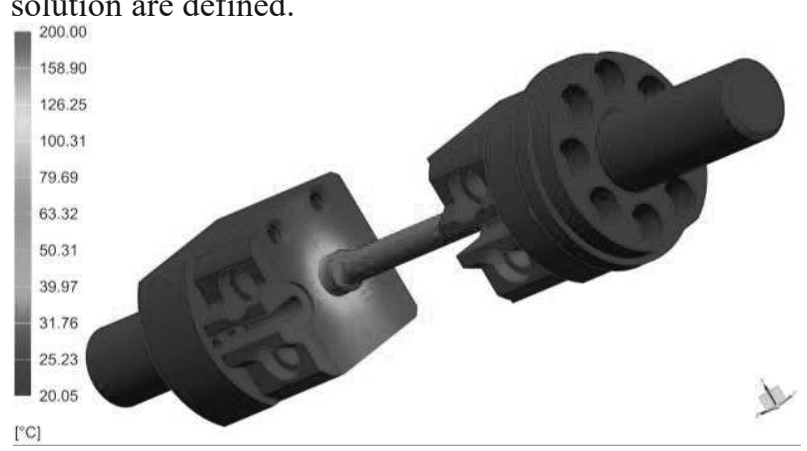

Fig. 6 Thermal field in time 300 second Simulation



— Temperature of speciemen $\left[{ }^{\circ} \mathrm{C}\right] \quad$ Heat load [W]

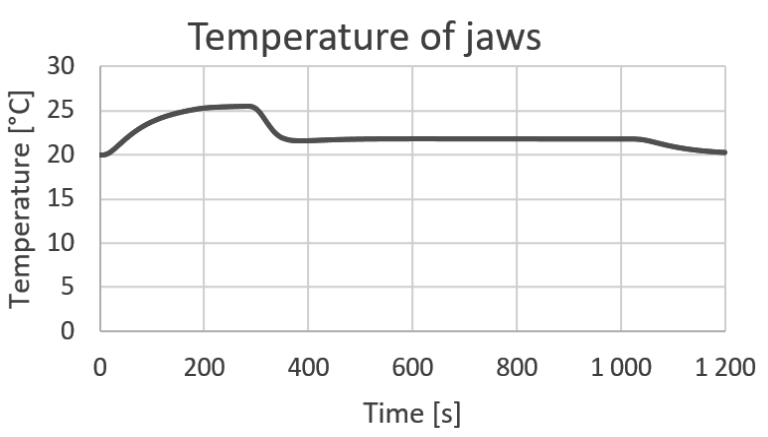

Fig. 7 Temperature curve of the jaws

The real test duration is 1200 seconds, transient solution is solved in this time schedule. The cooling liquid in the cooling circuit is pure water. Input thermal loads are defined by heat loading of real test rig. Real thermal load is moderated by the isothermal function of speciemen. It means, that heat load is general curve dependent on time. It is able in the Figure 6. Input fluid velocity is $0.5 \mathrm{~m} / \mathrm{s}$. Thermo-mechanical simulator uses compressed air and sprayed water to fast cooldown of speciemen. Fast cooldown by sprayed mixture in time 300 s is simulated by fast increase of convection thermal transfer coefficient
$4,5 \times 10^{-4} \mathrm{~W} / \mathrm{mm}^{2} \mathrm{~K}$. Results of simulation are in accordace with real test measurement. Requested temperature of jaw is under $30^{\circ} \mathrm{C}$. Time dependency of temperature of jaws can be seen in the Figure 7.

Simulation solution takes 410 seconds. Model consists of $50 \mathrm{~K} 3 \mathrm{D}$ elements and $11 \mathrm{~K} 2 \mathrm{D}$ elements for surface coating. Ambient temperature is set to $20^{\circ} \mathrm{C}$.

\section{Conclusion}

An innovative jaw design for a thermomechanical simulator has been designed to meet all demanding requirements. During the design, great emphasis was placed on minimizing displacement measurement errors. This has been achieved by rigid construction and minimizing the thickness of the isolating disk, since plastics have a significantly lower modulus of elasticity. This proposed tool will bring higher accuracy of measurement of deformation of test samples.

The results of the thermal simulation show that the cooling of the jaws is sufficient. Although the temperature of the sample exceeds $900^{\circ} \mathrm{C}$, the temperature of the jaws alone shall not exceed $30^{\circ} \mathrm{C}$ during the test.

This technical solution is protected as a utility model registred on The Industrial Property Office-Czech Republic [13].

\section{Acknowledgement}

The article has been prepared under project $\mathrm{L} 01502$ 'Development of the Regional Technological Institute' under the auspices of the National Sustainability Programme I of the Ministry of Education of the Czech Republic aimed at supporting research, experimental development and innovation.

\section{References}

[1] BUBLÍKOVÁ, D., MAŠEK, B., VOREL, I., JENÍČEK, Š. (2017). Stability of Retained Austenite in High-Strength Martensitic Steels with Low Ms Temperature. In: Manufacturing Technology, Vol. 17, No. 4, pp. 428-433. ISSN 1213-2489

[2] PEKOVIĆ, M., VOREL I., KÁŇA, J., OPATOVÁ, K. (2017) Evolution of Microstructure and Mechanical Properties in Steels during Isothermal Holding in the Region of Bainitic Transformation Temperature in Dependence on Silicon Content. In: Manufacturing Technology, Vol. 17, No. 4, pp. 549-555. ISSN 12132489

[3] CHVAL, Z., SEDLÁČEK, F., KEMKA, V. (2017) Usage of FEM simulations in design of piping systems. Manufacturing Technology. In: $\mathrm{Ma}$ nufacturing Technology, Vol. 17, No. 4, pp. 469473. ISSN 1213-2489

[4] JENICEK, S., VRATISLAV, K., KALINA, T., MASEK, B (2016). Use of waterjet in manufacturing test bars of high-strength steels, Annals of $D A A A M$ and Proceedings of the 27th DAAAM International Symposium, pp.0219-0224, Published 
by DAAAM International, ISBN 978-3-90273408-2, ISSN 1726-9679, Vienna, Austria

[5] KÁŇA, J., VOREL, I., RONEŠOVÁ, A. Simulator of Thermomechanical Treatment of Metals. In $D A A A M$ 2015. Vienna: DAAAM International Vienna, 2016. s. 0513-0518. ISBN: 978-3902734-07-5, ISSN: 1726-9679

[6] RONEŠOVÁ, A., MAŠEK, B., Digital generator of phase shift modulation, US Patent 7480 155, 2009, Available from: www.google.com.ar/patents/US7480155.

[7] MAREK, V. (2016) BASIC RESEARCH OF THERMAL TRANSFER SIMULATIONS, Annals of DAAAM and Proceedings of the International DAAAM Symposium, 2016, pp. 578-585. ISBN: 978-1-5108-3300-5, Mostar

[8] MAREK, V. (2017). Thermal simulations based on macro-models. 28th International DAAAM Symposium on Intelligent Manufacturing and $A u$ tomation 2017, Zadar, ISBN 978-3-902734-11-2

[9] RAZ, K., CHVAL, Z. (2016) Temperature monitoring during injection molding process, 11th International Conference of DAAAM Baltic Industrial Engineering; Tallinn; Estonia; Volume 2016-April, 2016, Pages 71-74, 20 April 2016 through 22 April 2016; Code 135813
[10] CHVAL, Z., RAZ, K. (2016) Effect of heat load on amechanical forging press. 27th DAAAM International Symposium on Intelligent Manufacturing and Automation, DAAAM 2016; Mostar; Bosnia and Herzegovina; Volume 27, Issue 1, 2016, Pages 344-348. 26 October 2016 through 29 October 2016; Code 125666

[11] CHVAL, Z. (2013) Effect of heat load on a forging press. 27th DAAAM International Symposium on Intelligent Manufacturing and Automation, DAAAM 2016; Mostar; Bosnia and Herzegovina; Volume 27, Issue 1, 2016, Pages 344-348, 26 October 2016 through 29 October 2016; Code 125666

[12] KALINA, T., HELlER, P., CHVAL, Z., SEDLÁČEK, F., KŘİŽEK M., BARTOŇ L., Numerical Simulation and Experimental Testing of Two-axle Chassis of Low-floor Trams, Manufacturing Technology: journal for science, research and production. Vol. 18, No. 2. Ústí nad Labem: Univerzita J.E. Purkyně v Ústí nad Labem, 2018. ISSN 1213-2489.

[13] KALINA T. Upínací čelistí (Clamping jaws), UŽITNÝ VZOR (UTILITY MODEL), n.doc.:33197, n.app..:2019-36482, 2019, owner: University of West Bohemia, registered on The Industrial Property Office, Czech Republic, Online: https://isdv.upv.cz/doc/FullFiles/UtilityModels/FullDocuments/FDUM0033/uv033197.pdf 